\title{
Previous Exposure to Glucose Enhances Somatostatin Secretion from the Isolated Perfused Rat Pancreas
}

\author{
V. Grill, M. Rundfeldt, and S. Efendić \\ Department of Endocrinology, Karolinska Hospital, Stockholm, Sweden
}

\begin{abstract}
Summary. Previous exposure to glucose enhances insulin and depresses glucagon secretion by the pancreas. We have investigated whether secretion of somatostatin is also influenced by a glucose priming effect. In perfused rat pancreas from $36 \mathrm{~h}$ fasted rats a $5 \mathrm{~min}$ pulse of arginine $(8 \mathrm{mmol} / \mathrm{l})$ rapidly elicited a peak of somatostatin release. A similar somatostatin response was evoked by a second, identical, pulse of arginine after perfusion with "basal" glucose $(3.9 \mathrm{mmol} / \mathrm{l})$ for $45 \mathrm{~min}$. On the other hand when $27.7 \mathrm{mmol} / \mathrm{l} \mathrm{D}$-glucose, was administered for $20 \mathrm{~min}$ between arginine pulses, there was significant stimulation of somatostatin secretion. When arginine was re-introduced $15 \mathrm{~min}$ after the cessation of the pulse of elevated glucose the magnitude of the arginineinduced peak ( $\min 0-2$ of stimulation) was increased from $16.2 \pm 4.1$ to $33.1 \pm 4.7 \mathrm{pg} / 2 \mathrm{~min}, \mathrm{p}<0.01$, relative to the first stimulation with arginine. None of these effects of glucose could be reproduced by Dgalactose. The somatostatin response to arginine was higher in pancreata from fed than from $36 \mathrm{~h}$ fasted animals as was also basal release ( $22.8 \pm 5.0$ vs $9.0 \pm$ $2.0 \mathrm{pg} / \mathrm{min}$ ). In the fed state the response to the second pulse of arginine was however reduced by $50 \%$ after perfusion with "basal" glucose. This decrease in responsiveness was counteracted by perfusion with $27.7 \mathrm{mmol} / 1$ glucose for $20 \mathrm{~min}$ between the arginine pulses. It is concluded that previous exposure to an elevated concentration of glucose enhances D-cell responsiveness to arginine in the fasted as well as the fed state.
\end{abstract}

Key words: Somatostatin release, D-cell, insulin release, glucagon release, glucose priming, fasting, glucose metabolism, starvation, glucose homeostasis, perfused rat pancreas.

Glucose promptly stimulates insulin secretion and amplifies the insulinotropic effect of other agents whereas glucagon secretion is affected in a reciprocal fashion [1]. The magnitude of these acute effects of glucose on the B-and A-cells is however strikingly reinforced by a short previous exposure to the sugar [2-5]. Such exposure increases the responsiveness of the B- [2-4] and decreases that of the A-cells [5] thus demonstrating priming or "memory" effects of glucose.

Somatostatin has been identified as the hormone present in the D-cells of islets of Langerhans [6, 7]. With the advent of sensitive radioimmunoassays, secretion of somatostatin has been found to be stimulated promptly by high concentrations of glucose [8-10]. The present study was undertaken in order to test whether also a priming effect of glucose could be demonstrated in the D-cells concomitant with the effects already documented on insulin and glucagon secretion. The isolated perfused pancreas of the rat was used since this preparation retains a high sensitivity of A, B- and D-cells to stimulation. Arginine is a potent stimulator of insulin and glucagon [1], and somatostatin $[10,11]$ secretion; this amino acid was thus considered as a suitable agent with which to test simultaneously the effects of priming with glucose on the release of all three hormones. To test whether a priming effect of glucose was restricted or not to the fasted state, the experiments were carried out in pancreata from $36 \mathrm{~h}$ fasted as well as from fed animals.

\section{Material and Methods}

\section{Animals, Experimental Procedure}

Male Sprague-Dawley rats weighing $180-220 \mathrm{~g}$ were obtained from Anticimex, Stockholm. They were either fasted for 36 hours or fed ad libitum. The pancreata were isolated free from all surrounding tissue by the technique of Loubatières [12]. The perfusion medium was a Krebs-Henseleit-bicarbonate medium [13] supplemented with $20 \mathrm{~g} / \mathrm{l}$ of bovine albumin and $3.9 \mathrm{mmol} / 1$ of glucose. The medium was introduced through the abdominal aorta and pumped through the pancreas without recycling at a flow rate of approximately $2.0 \mathrm{ml} / \mathrm{min}$. 
The study protocols are illustrated in Figure 1. The design of the experiments was guided by the need to obviate interexperimental variation between different preparations. Such variation was considerable in previous studies $[5,14]$ as well as in the present one (Table 1). Possible causes include seasonal influences on the rats used, the use of different batches of albumin [15] as well as the interassay variation between the radioimmunological determinations. The basic experimental protocol thus consisted of the administration of two identical $5 \mathrm{~min}$ pulses of $8 \mathrm{mmol} / \mathrm{l}$ of arginine. First and second pulse responses could then be compared within the same experiment. During an intervening period of $45 \mathrm{~min}$, the glucose concentration was either kept at $3.9 \mathrm{mmol} / \mathrm{l}$ (protocol 1) or intermittently raised for $20 \mathrm{~min}$ to $27.7 \mathrm{mmol} / \mathrm{l}$ (protocol 2). The pulse of elevated glucose was terminated $15 \mathrm{~min}$

1
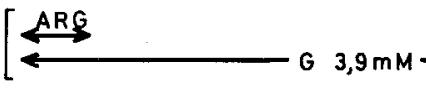

2

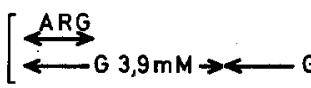

G $27,7 \mathrm{mM}$

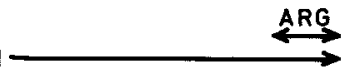

3

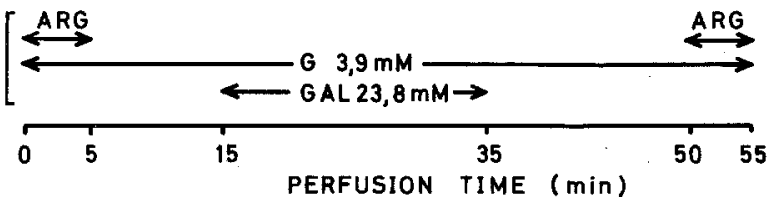

Fig. 1. Experimental protocol for perfusion studies. A $15 \mathrm{~min}$ period of pre-perfusion (not shown in figures) was allowed before the start of the experimental protocols. The latter time-point was designated as min zero. ARG $=$ arginine, $\mathrm{G}=\mathrm{D}$-glucose, $\mathrm{GAL}$ $=$ galactose before the second pulse of arginine. In one experimental series the glucose pulse was substituted by galactose (protocol 3). Experiments using protocols 1 and 2 in fed rats and protocol 3 in fasted rats were carried out 9 months later than the rest of experiments.

Samples were obtained at $60 \mathrm{~s}$ intervals during stimulation with arginine. The eluate from the entire pulse of glucose or galactose was pooled and a single aliquot was retained. $0.5 \mathrm{ml}$ of samples were collected into pre-chilled tubes containing $0.1 \mathrm{ml}$ of Trasylol $(10000 \mathrm{IU} / \mathrm{ml})$, then frozen and stored at $-20^{\circ} \mathrm{C}$.

\section{Radioimmunoassay}

Insulin was assayed as previously described [16]. Rat insulin which served as standard was a gift from Dr J. Schlichtkrull, Novo Industries, Bagsvaerd, Denmark. The antibodies used were raised against porcine insulin. Glucagon was assayed as described [17] using $30 \mathrm{~K}$ antibody (several batches), raised against porcine glucagon and obtained from Dr. Unger, Dallas, Texas. Porcine glucagon served as standard. Somatostatin was assayed using antibodies raised in the rabbit against cyclic somatostatin as described $[10,18]$. The validity of the somatostatin assay was ascertained by parallel serial dilution curves of standards and somatostatin-reactive material. Neither $8 \mathrm{mmol} / 1$ arginine nor $27.7 \mathrm{mmol} / 1$ glucose influenced the binding of somatostatin to the antibody. The limit of sensitivity was $0.3 \mathrm{pg} /$ assay tube or $3 \mathrm{pg} / \mathrm{ml}$ of perfusate. The inter- and intrassay coefficients of variation were $26 \%$ and $18 \%$ respectively.

\section{Presentation of Results}

These are expressed as mean \pm SEM. Levels of significance were calculated by Student's t-test (two-tail) using paired differences when applicable.

Table 1. Effects of priming with glucose on arginine-induced insulin, glucagon and somatostatin secretion from fed and $36 \mathrm{~h}$ fasted animals. Except for experiments with galactose $(n=7)$, results are derived from data presented in Figures 2 and 3. Mean \pm SEM of the integrated release above baseline during the stimulation with arginine

\begin{tabular}{|c|c|c|c|c|c|c|}
\hline \multirow[t]{2}{*}{ Conditions } & \multicolumn{2}{|c|}{ Insulin $\mu \mathrm{U} / 5 \mathrm{~min}$} & \multicolumn{2}{|c|}{ Glucagon $\mathrm{ng} / 5 \mathrm{~min}$} & \multicolumn{2}{|c|}{ Somatostatin $\mathrm{pg} / 5 \mathrm{~min}$} \\
\hline & $\begin{array}{l}\text { Arginine } \\
\text { 1st pulse }\end{array}$ & $\begin{array}{l}\text { Arginine } \\
\text { 2nd pulse }\end{array}$ & $\begin{array}{l}\text { Arginine } \\
\text { 1st pulse }\end{array}$ & $\begin{array}{l}\text { Arginine } \\
\text { 2nd pulse }\end{array}$ & $\begin{array}{l}\text { Arginine } \\
\text { 1st pulse }\end{array}$ & $\begin{array}{l}\text { Arginine } \\
\text { 2nd pulse }\end{array}$ \\
\hline $\begin{array}{l}\text { Fasted } 36 h \\
\text { Control, protocol } 1 \\
\text { (glucose } 3.9 \mathrm{mmol} / 1 \\
\min 0-55 \text { ) }\end{array}$ & $771 \pm 120$ & $463 \pm 109^{b}$ & $8.6 \pm 1.1$ & $8.8 \pm 1.6$ & $45.0 \pm 8.9$ & $42.0 \pm 8.9$ \\
\hline $\begin{array}{l}\text { Priming, protocol } 2 \\
\text { (glucose } 27.7 \mathrm{mmol} / 1 \\
\min 15-35 \text { ) }\end{array}$ & $776 \pm 198$ & $1801 \pm 181^{\mathrm{c}}$ & $8.3 \pm 0.8$ & $4.5 \pm 0.4^{\mathrm{c}}$ & $36.7 \pm 8.3$ & $47.7 \pm 10.7^{\mathrm{a}}$ \\
\hline $\begin{array}{l}\text { Galactose, protocol } 3 \\
(23.8 \mathrm{mmol} / 1 \text { galactose } \\
\min 15-35)\end{array}$ & $127 \pm 45$ & $82 \pm 36^{b}$ & $4.3 \pm 1.1$ & $4.6 \pm 1.4$ & $30.3 \pm 15.9$ & $29.3 \pm 11.3$ \\
\hline $\begin{array}{l}\text { Fed } \\
\text { Control, protocol } 1 \\
\text { (glucose } 3.9 \mathrm{mmol} / 1 \\
\min 0-55 \text { ) }\end{array}$ & $2824 \pm 493$ & $1522 \pm \cdot 264^{b}$ & $6.4 \pm 1.1$ & $6.2 \pm 1.0$ & $73.5 \pm 23.2$ & $32.0 \pm 12.8^{\mathrm{c}}$ \\
\hline $\begin{array}{l}\text { Priming, protocol } 2 \\
\text { (glucose } 27.7 \mathrm{mmol} / 1 \\
\text { min } 15-35 \text { ) }\end{array}$ & $4542 \pm 439$ & $9636 \pm 1529^{c}$ & $5.8 \pm 1.2$ & $3.7 \pm 0.6^{c}$ & $98.8 \pm 24.5$ & $104.4 \pm 13.0$ \\
\hline
\end{tabular}

${ }^{\mathrm{a}} \mathrm{p}<0.05,{ }^{\mathrm{b}} \mathrm{p}<0.01,{ }^{\mathrm{c}} \mathrm{p}<0.001$ significance of differences between 1 st and 2 nd pulses of arginine (Student's t-test, paired differences) 
CONTROL
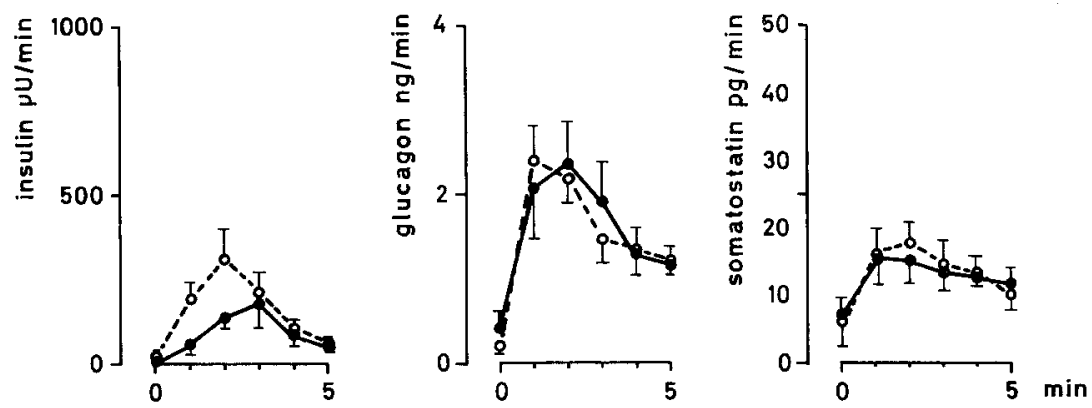

\section{GLUCOSE PRIMING}

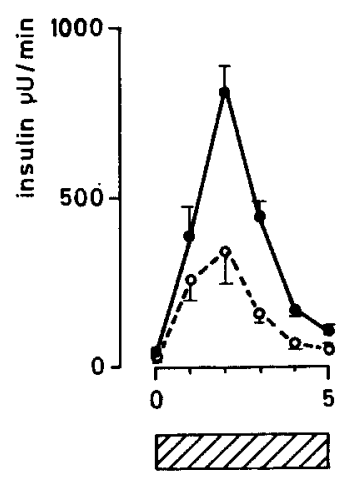

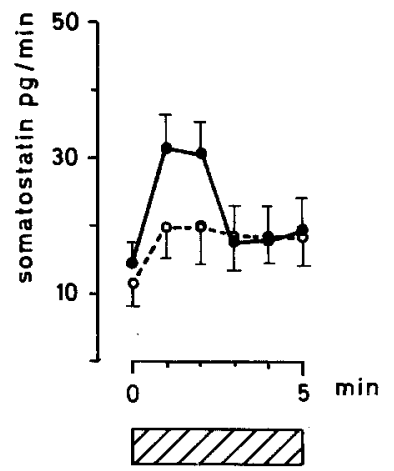

Fig. 2. Effects of priming with glucose after $36 \mathrm{~h}$ of fasting on arginine-induced secretion of immunoreactive insulin, glucagon and somatostatin. Protocols 1 and 2 were used. Two successive pulses of $8 \mathrm{mmol} / 1$ of arginine were administered $45 \mathrm{~min}$ apart and the glucose concentration was either kept at $3.9 \mathrm{mmol} / 1$ throughout the experiment (upper panel, control) or intermittently raised to $27.7 \mathrm{mmol} / \mathrm{l}$ for $20 \mathrm{~min}$ between pulses (lower panel, glucose priming). Results are expressed as the mean \pm SEM of control $(\mathrm{n}=5)$ or glucose priming $(\mathrm{n}=$ 8) experiments. $Z \triangle=$ period of arginine administration, $-O-=1$ st pulse, $-=2$ nd pulse of amino acid

\section{Results}

\section{Fasted Rats (36 hours)}

A 5 minute pulse of $8 \mathrm{mmol} / \mathrm{l}$ of arginine elicited a peak and decline pattern of release of insulin, glucagon and somatostatin (Fig. 2 and Table 1). Further perfusion with $3.9 \mathrm{mmol} / 1$ glucose for 45 minutes did not significantly alter the basal release of glucagon or somatostatin nor the response to a second pulse of arginine. Basal insulin release was however significantly diminished (from $20 \pm 2$ at 0 minutes to $11 \pm$ $4 \mu \mathrm{U} / \mathrm{min}$ at 50 minutes, $\mathrm{p}<0.01$ ) as was also the stimulated secretion due to re-introduction of arginine (Table 1).

When the concentration of glucose was intermittently raised from 3.9 to $27.7 \mathrm{mmol} / 1$ for 20 minutes between the two pulses of arginine, the secretion of insulin and somatostatin was stimulated and that of glucagon inhibited during the presence of high glucose (Table 2). When a second pulse of arginine was presented $15 \mathrm{~min}$ after the cessation of the glucose pulse, the insulin response was two-fold increased at all time points while glucagon release was inhibited by $45 \%$ (p $<0.01$, Fig. 2 and Table 1). Simultaneously, glucose priming significantly increased somatostatin release over the $5 \mathrm{~min}$ period of stimu- lation with arginine $(\mathrm{p}<0.05$, Table 1$)$. The effect of priming was to enhance the magnitude of the arginine induced peak $(\min 0-2)$ which was increased from $16.2 \pm 4.1$ to $33.1 \pm 4.7 \mathrm{pg} / 2 \mathrm{~min}, \mathrm{p}<0.01$.

The specificity of the priming effects of glucose were tested in experiments where $27.7 \mathrm{mmol} / \mathrm{l}$ of $\mathrm{D}$ glucose was substituted for by $23.8 \mathrm{mmol} / 1$ of $\mathrm{D}$ galactose in the continued presence of $3.9 \mathrm{mmol} / 1$ of glucose (protocol 3). Galactose together with "basal" glucose, did not induce insulin, glucagon or somatostatin release, (results not shown), nor did this isomer of glucose induce any of the priming effects observed after glucose (Table 1).

\section{Fed Rats}

Differences were noted in basal as well as stimulated secretion rates in pancreata from fed vs $36 \mathrm{~h}$ fasted animals. When calculated from all experiments (fasted $\mathrm{n}=20$, fed $\mathrm{n}=13$ ) the basal secretion of insulin was increased by feeding from $14 \pm 4$ to $37 \pm$ $3 \mu \mathrm{U} / \mathrm{min}, \mathrm{p}<0.001$ and somatostatin secretion from $9.2 \pm 2.0$ to $22.8 \pm 5.0 \mathrm{pg} / \mathrm{min}, \mathrm{p}<0.01$, while basal release of glucagon was decreased from $0.45 \pm 0.08$ to $0.11 \pm 0.04 \mathrm{ng} / \mathrm{min}$. The effects of feeding on the insulin and somatostatin response to arginine were to increase the insulin release from $572 \pm 112$ to 4044 
Table 2. Effects of glucose on A, B and D-cell secretion in the fed and $36 \mathrm{~h}$ fasted state. Results are obtained from the same experiments depicted in Figures 2 and 3 and demonstrate the effects of $27.7 \mathrm{mmol} / 1$ of glucose on insulin, glucagon and somatostatin release during its presence for $20 \mathrm{~min}$. The glucose stimulus was administered between two pulses of arginine (protocol 2, Fig. 1). Data are presented as the mean \pm SEM of the glucose effects above basal release

\begin{tabular}{llccc}
\hline Conditions & $\begin{array}{l}\text { Number of } \\
\text { experiments }\end{array}$ & Insulin, $\mu \mathrm{U} / \mathrm{min}$ & Glucagon, ng/min & Somatostatin, pg/min \\
\hline Fasted $36 \mathrm{~h}$ & 8 & $144 \pm 17$ & $-0.3 \pm 0.2$ & $9.5 \pm 2.7$ \\
Fed & 7 & $918 \pm 223^{\mathrm{c}}$ & $\pm 0.0 \pm 0.0$ & $25.6 \pm 6.1^{\mathrm{a}}$ \\
\hline
\end{tabular}

${ }^{\mathrm{a}} \mathrm{p}<0.05,{ }^{\mathrm{c}} \mathrm{p}<0.001$, significance of difference between fed and fasted state (Student's t-test, non-paired differences)

$\pm 467 \mu \mathrm{U} / 5 \mathrm{~min}, \mathrm{p}<0.001$ and the somatostatin release from $36.5 \pm 6.6$ to $86.6 \pm 17.4 \mathrm{pg} / 5 \mathrm{~min}, \mathrm{p}$ $<0.005$. Also in the experiments where $27.7 \mathrm{mmol} / \mathrm{l}$ of glucose was administered, the insulin release was 6 -fold $(\mathrm{p}<0.001)$ and somatostatin 2 -fold $(\mathrm{p}<0.05)$ higher in the fed than in the fasted state (Table 2).

In contrast to the findings in $36 \mathrm{~h}$ fasted animals, the basal secretion of somatostatin diminished during the two-pulse protocol in the fed state (from $23.0 \pm$ 11.5 at zero minutes to $4.7 \pm 3.9 \mathrm{pg} / \mathrm{min}$ at 50 minutes). Also the response to a second pulse of arginine was markedly reduced (by $50 \%$, Fig. 3 , Table 1). This deterioration of the arginine response was completely prevented when $27.7 \mathrm{mmol} / \mathrm{l}$ of glucose was administered between the arginine pulses. Relative to the first arginine pulse within the same experiment, the somatostatin response was however unaltered when arginine was re-introduced after glucose in the fed state.

\section{Discussion}

The present study demonstrates priming effects of glucose on insulin, glucagon and somatostatin secretion from the pancreas of $36 \mathrm{~h}$ fasted as well as from fed rats when measured $15 \mathrm{~min}$ after the cessation of a glucose stimulus. In the case of somatostatin the response was markedly enhanced in fasted and restored in fed rats. The effects of glucose could not be reproduced by an equimolar concentration of $\mathrm{D}$ galactose, an isomer of glucose which is not metabolised in islets [19]. Thus it could be inferred that the priming effects of glucose were not secondary to a non-specific change of osmolality in the perfusion medium.

In control experiments, the administration of arginine depressed subsequent insulin release in the fasted and fed state and somatostatin release in the fed state. An inhibitory effect of arginine on subsequent insulin release was noted also in man [20] where the second of two consecutive arginine pulses elicited a smaller insulin release than the first one. The cellular mechanisms behind the negative effects of arginine are not clear. With regard to insulin secre- tion, the inhibition subsides with time [20]. This may explain why no inhibition was noted in a previous series [5] where arginine was re-introduced after a longer time-period than in the present study.

The fact that priming can be demonstrated concomittantly in A, B and D-cells is compatible with the notion that similar mechanisms are operative. The common feature of enhancement of the acute effects of glucose (i. e. increased stimulation of insulin and somatostatin secretion, increased inhibition of glucagon secretion) may be taken as additional, though circumstantial, evidence along the same line. Although the effect of other secretagogues than glucose on D-cell secretion were not tested, previous studies indicate that the metabolism of glucose is essential for the induction of priming at least in A [5] and B-cells [4], since glucose cannot be substituted for by secretagogues which are non-metabolisable such as arginine [21]. It seems possible that the generation of high-energy phosphate intermediates may be of significance since ATP levels are augmented after priming (Grill and Ågren, unpublished observations). Alternatively, priming may be mediated through increased synthesis of proteins participating in the process of exocytosis. In this context it should be noted that the time-scale of induction of a priming effect is probably too short to allow altered biosynthesis of the respective hormones to be of importance $[22,23]$.

Paracrine effects have been suggested to supplement the systemic effects of islet hormones [24]. Experimental evidence does support the notion of intercellular communications between islet cells [25]. However, the present results concerning priming cannot be explained by postulating local interactions between the A, B or D-cells. For example, while data from $36 \mathrm{~h}$ fasted animals, taken alone, may suggest that heightened secretion of somatostatin could mediate the inhibitory effect by glucose priming on glucagon secretion, this does not fit with the data from fed animals where priming with glucose inhibited arginine-induced glucagon secretion without any change in the somatostatin response within the same experiment. 

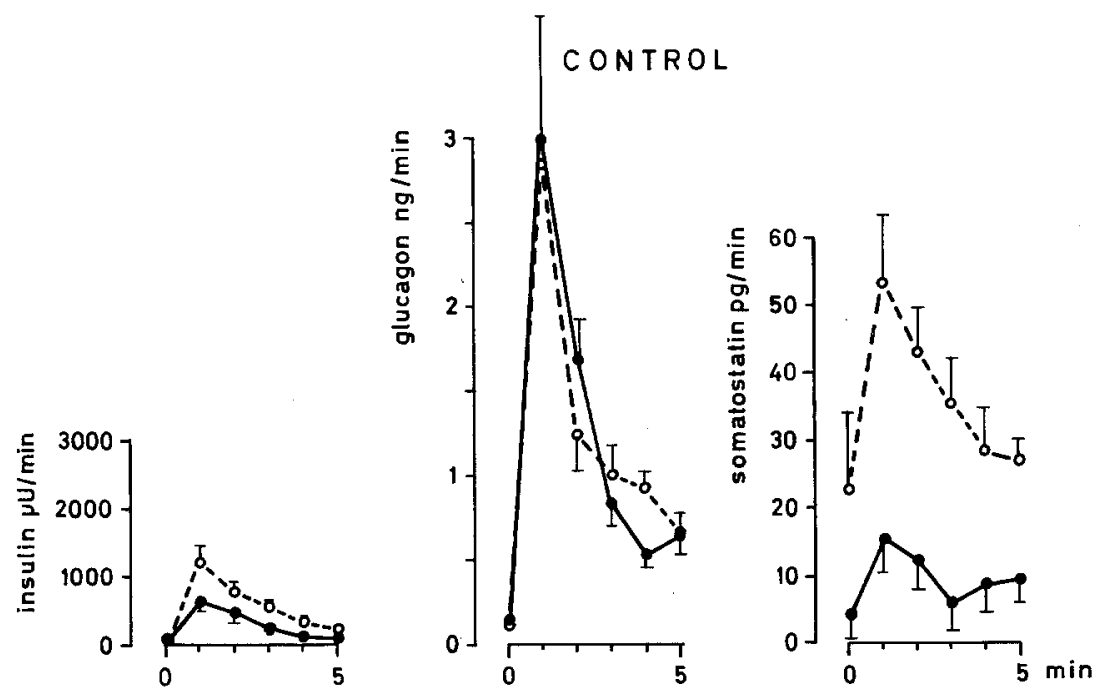

GLUCOSE PRIMING
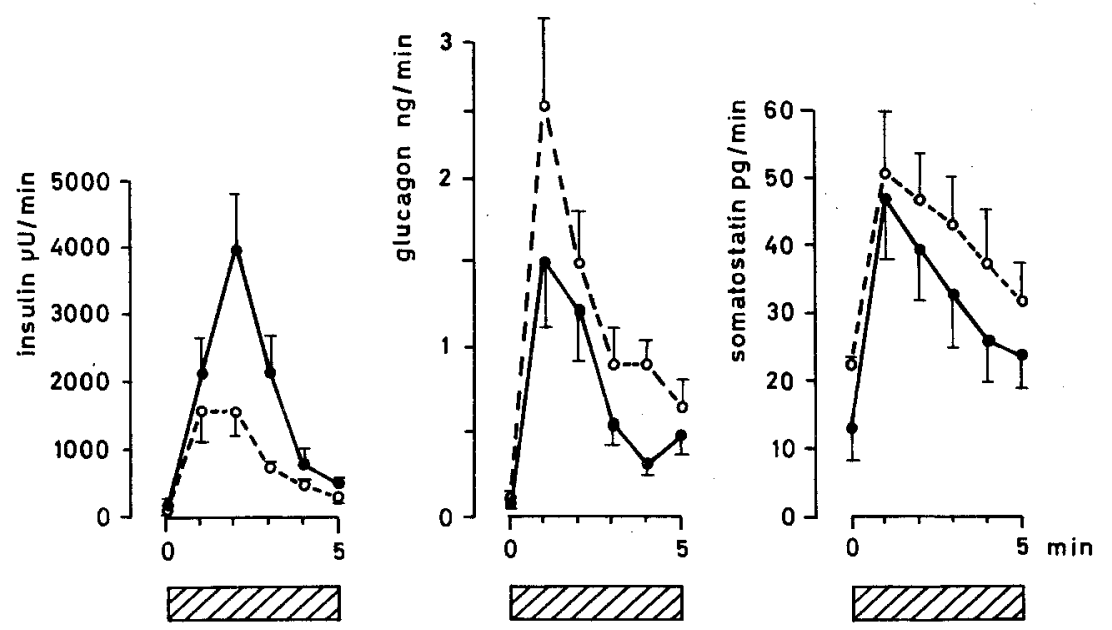

Fig. 3. Effects of priming with glucose in the fed state on arginine-induced secretion of immunoreactive insulin, glucagon and somatostatin. Protocols 1 (control) and 2 (glucose priming) were used. Results are expressed as the mean \pm SEM of $n=6$ and $\mathrm{n}=7$ experiments performed according to respective protocols. Symbols as in Figure 2

The physiological role of the priming effects of glucose are unknown. It may be speculated that they form part of adaptive mechanisms for the preservation of glucose homeostasis which act by reducing the impact of a carbohydrate challenge. Increased insulin release lowers blood glucose by increasing hepatic and peripheral uptake of glucose while a lesser glucagon secretion enhances the insulin effect on the liver. Portally delivered somatostatin could further increase glucose disposal by increasing the clearance rate of insulin over the splanchnic area [26] or by inhibiting the output of glucose from the liver (although the latter effect on the liver has so far only been shown using pharmacological concentrations of the hormone [27]). Furthermore, splanchnic somatostatin could decrease the rate of entry of carbohydrates into the organism by prolonging the transit time of nutrients in the gut [28].
In vivo the secretion of insulin is higher [29] and that of glucagon lower $[30,31]$ in the fed than in the fasted state. Feeding also increases the secretion of somatostatin into the portal vein [32]. Although these changes are qualitatively similar to those observed after priming, the mechanisms behind them are probably not identical because of the different time-scale used for demonstrating feeding and priming effects. In this context, it is also interesting to note that not only insulin but also the secretion of somatostatin was enhanced in the fed state in our perfused pancreas preparation. The latter observation is in contrast to results obtained in isolated islets [33] but in accordance with other data obtained from the perfused rat pancreas [34]. However, we do not wish to over-emphasise these and other quantitative differences between the response from fed or fasted pancreatic preparations since our protocols were not designed primarily to test for such differences. 
Acknowledgements. This work was supported by grants from the Swedish Medical Research Council (grants no B80-04540-06A and B80-19X-00034-16B), the Swedish Diabetes Association, Nordisk Insulinfond and the Ake Wibergs Foundation. The technical assistance of Miss Riita Partanen and Mrs Anette Wendt is gratefully acknowledged.

\section{References}

1. Gerich JE, Charles MA, Grodsky GM (1976) Regulation of pancreatic insulin and glucagon secretion. Annu Rev Physiol 38: $353-388$

2. Grodsky GM, Curry D, Landahl H, Bennett L (1969) Further studies on the dynamic aspects of insulin release in vitro with evidence for a two-compartmental storage system. Acta Diabetol Lat 6 [Suppl 1]: 554-579

3. Cerasi $E$ (1975) Potentiation of insulin release by glucose in man. I. Quantitative analysis of the enhancement of glucoseinduced insulin secretion by pretreatment with glucose in normal subjects. Acta Endocrinol (Kbh) 79: 483-501

4. Grill V, Adamson U, Cerasi E (1978) Immediate and timedependent effects of glucose on insulin release from rat pancreatic tissue. Evidence for different mechanisms of action. $J$ Clin Invest 61: 1034-1043

5. Grill V, Adamson U, Rundfeldt $M$, Andersson S, Cerasi $E$ (1979) The glucose memory of pancreatic $B$ and $A_{2}$ cells. Evidence for common time-dependent actions of glucose on insulin and glucagon secretion. $J$ Clin Invest 64: 700-707

6. Luft R, Efendić S, Hökfelt T, Johansson O, Arimura A (1974) Immunohistochemical evidence for the localization of somatostatin-like immunoreactivity in a cell population of pancreatic islets. Med Biol 4: 428-430

7. Dubois MP (1975) Immunoreactive somatostatin is present in discrete cells of the endocrine pancreas. Proc Natl Acad Sci USA $72 ; 1340-1343$

8. Schauder P, McIntosh C, Arends J, Arnold R, Frerichs H, Creutzfeldt W (1976) Somatostatin and insulin release from isolated rat pancreatic islets stimulated by glucose. FEBS Lett 68: $225-227$

9. Ipp E, Dobbs RE, Arimura A, Harris V, Unger RH (1977) Release of immunoreactive somatostatin from the pancreas in response to glucose, amino acids, pancreozymin - cholecystokinin and tolbutamide. J Clin Invest 60: 760-765

10. Efendić S, Nylén A, Roovete A, Uvnäs-Wallensten K (1978) Effects of glucose and arginine on the release of immunoreactive somatostatin from the isolated perfused rat pancreas. FEBS Lett 92: 33-35

11. Patton GS, Ipp E, Dobbs RE, Orci L, Vale W, Unger RH (1976) Response of pancreatic immunoreactive somatostatin (IRS) to arginine. Life Sci 19:1957-1960

12. Loubatières A, Mariani MM, Ribes G, de Malbosc H (1969) Experimental study on glibenclamide (HB 419), a new, particulary active, hypoglycaemic sulphonamide. I. Betacytotropic action and insulin secretion. Diabetologia $5: 1-10$

13. Umbreit WW, Burris RH, Stauffer JF (1957) In: Manometric techniques. Burgess Publish $\mathrm{Co}$, Minneapolis Minnesota, $\mathrm{p}$ 149

14. Landgraf R, Landgraf-Leurs MMC, Rörl R (1974) L-leucine and $L$-phenylalanine induced insulin release and the influence of D-glucose: Kinetic studies with the perfused rat pancreas. Diabetologia 10: $415-420$

15. Leclercq-Meyer V, Marchand $J$, Leclercq R, Malaisse WJ (1976) Glucagon and insulin release by the in vitro perfused rat pancreas. Diabète Metab 2: 57-65

16. Herbert V, Lau KS, Gottlieb CW, Bleicher SJ (1965) Coated charcoal immunoassay of insulin. J Clin Endocrinol Metab 25: $1375-1384$
17. Faloona GR, Unger RH (1974) Glucagon. Radioimmunoassay technique. In: Jaffe BM, Behrman HR (eds) Methods of hormone radioimmunoassay. Academic Press, London New York, p. 324-326

18. Efendić S, Enzmann F, Nylén A, Uvnäs-Wallensten K, Luft R (1979) Effect of glucose/sulfonylurea interaction on release of insulin, glucagon and somatostatin from isolated perfused rat pancreas. Proc Natl Acad Sci USA 76: 5901-5904

19. Jarrett RJ, Keen $H$ (1968) Oxidation of sugars, other than glucose, by isolated mammalian islets of Langerhans. Metabolism 17: 155-157

20. Efendić S, Lins PE, Cerasi E (1979) Potentiation and inhibition of insulin release in man following priming with glucose and with arginine - effect of somatostatin. Acta Endocrinol (Kbh) 90: 259-271

21. Hellman B, Sehlin $\mathbf{J}$, Täljedal I-B (1971) Effects of glucose and other modifiers of insulin release on the oxidative metabolism of amino acids in micro-dissected pancreatic islets. Biochem J 123: 513-521

22. Howell SL, Taylor KW (1967) The secretion of newly synthesized insulin in vitro. Biochem J 102: 922-927

23. Sando H, Grodsky GM (1973) Dynamic synthesis and release of insulin and proinsulin from perifused islets. Diabetes 22: 354-361

24. Samols $E$, Marri $G$, Marks $V$ (1965) Promotion of insulin secretion by glucagon. Lancet II: 415-416

25. Kohen E, Kohen C, Thorell B, Mintz D, Rabinovitch A (1979) Intercellular communication in pancreatic islet monolayer cultures: A microfluorometric study. Science 204: 862-865

26. Ishida T, Röjdmark S, Bloom G, Chou MCY, Field JB (1980) The effect of somatostatin on the hepatic extraction of insulin and glucagon in the anesthetized dog. Endocrinology 106: 220-230

27. Sacks H, Waligora K, Matthews J, Pimstone BL (1977) Inhibition by somatostatin of glucagon-induced glucose release from the isolated perfused rat liver. Endocrinology 101: 1751-1759

28. Shusdziarra V, Harris V, Arimura A, Unger RH (1979) Evidence for a role of splanchnic somatostatin in the homeostasis of ingested nutrients. Endocrinology 104: 1705-1708

29. Grey NJ, Goldring S, Kipnis DM (1970) The effect of fasting, diet and actinomycin $\mathrm{D}$ on insulin secretion in the rat. $\mathrm{J}$ Clin Invest 49: 881-889

30. Müller WA, Faloona GR, Unger RH (1971) The influence of the antecedent diet upon glucagon and insulin secretion. $N$ Engl J Med 285: 1449-1454

31. Assan R, Tchoubroutsky G, Tiengo A (1972) Influence of some nutrients and metabolic substrates on glucagon secretion. In: Froesch ER, Judkin J (eds) Nutrition and diabetes mellitus, VI Capri Conference. Il Ponte, Milano, I: 351-372

32. Shapiro B, Berelowitz M, Pimstone BL, Kronheim S, Sheppard $M$ (1979) Tissue and serum somatostatin-like immunoreactivity in fed, $15 \mathrm{~h}$-fasted and $72 \mathrm{~h}$-fasted rats. Diabetes $28: 182-185$

33. Schauder P, MeIntosh C, Arends J, Frerichs H (1979) Effect of fasting on the release of insulin and somatostatin from perifused islets of Langerhans. Diabetes 28: 204-207

34. Seino S, Sakurai H, Seino Y, Tsuda K, Tanigawa K, Kuzuya H, Goto Y, Imura H (1980) Starvation-induced changes of somatostatin, glucagon and insulin secretion from the isolated perfused rat pancreas. Diabetes 29: 323-326

Received: July 17, 1980,

and in revised form: October 28,1980

Dr. V. Grill

Department of Endocrinology

Karolinska Sjukhuset

S-104 01 Stockholm 60

Sweden 